(C) The Author(s), 2021. Published by Cambridge University Press. This is an Open Access article, distributed under the terms of the Creative Commons Attribution licence (http://creativecommons.org/licenses/by/4.0/), which permits unrestricted re-use, distribution, and reproduction in any medium, provided the original work is properly cited. 0361-6843/21

\title{
RIGHTS AS RATIONALIZATIONS? PSYCHOLOGICAL DEBUNKING OF BELIEFS ABOUT HUMAN RIGHTS
}

\author{
Christoph Bublitz (D) \\ University of Hamburg, Faculty of Law, Hamburg, \\ Germany
}

\begin{abstract}
This paper explores a novel type of argument in legal theory-a psychological debunking argument-by the example of the justification of human rights and based on a psychological dual-process model of decision-making. Debunking arguments undermine confidence in a belief because of shortcomings of the empirical conditions under which it was formed. They thereby open a route from the descriptive to the evaluative, from Is to Ought, without illicitly crossing metaethical waters since they involve normative premises. As they are epistemic, they cannot replace substantive arguments on the merits. However, they may be useful when substantive arguments are stalled or the necessity to make a judgment precludes further discussions.

The controversial justification of human rights is a good test case for debunking arguments. The challenge is to find features in the formation of beliefs about human rights that undermine their epistemic justification. Some psychologists claim that relevant beliefs arise from the rationalization of intuitions. This process is ill-suited to generate correct beliefs; so formed beliefs may be debunked. This also shows how legal reasoning might be improved.
\end{abstract}

\section{INTRODUCTION}

This paper explores the possibility of a novel type of argument in legal theory - a psychological debunking argument-by the example of the justification of human rights, and on the basis of a recent psychological model of moral decision-making. Debunking arguments have gained prominence in recent years in philosophy, particularly in ethics. ${ }^{1}$ Their intriguing feature is that they draw on empirical findings about the psychology of

1. Shaun Nichols, Process Debunking and Ethics, 124 Ethics 727 (2014); Hanno Sauer, Debunking Arguments in Ethics (2018); Folke Tersman, Debunking and Disagreement, 52 Noûs 754 (2017); Guy Kahane, Evolutionary Debunking Arguments, 45 Nô̂s 103 (2011); Victor Kumar \& Joshua May, How to Debunk Moral Beliefs, in Methodology and Moral Philosophy 25 
reasoning to assess the normative persuasiveness of the conclusions of that reasoning. They thereby open a route from the descriptive to the evaluative, from moral psychology to moral philosophy. The question of present interest is whether this route might extend to the law. Debunking arguments do not, I hasten to add, illicitly cross from Is to Ought since they involve normative premises. The extent to which debunking arguments are successful or interesting, as well as their broader consequences, is the subject of ongoing philosophical debates. The following applies one of the main types of those arguments—a dual-process debunking argument-to the law, more precisely, to a venerable topic of legal theory, the justification of specific human rights, old or new. Accordingly, this paper explores whether the way a decision-maker such as a judge reasons about the justification of a specific human right has something interesting to say about the correctness of the results of this reasoning, or more precisely, about whether the reasoner is justified in believing in their correctness. ${ }^{2}$ I shall argue that it does, as some psychological processes are prone to lead to unreliable outputs, undermining confidence in the resulting beliefs.

This article is based on a recent psychological model of moral decisionmaking and the genesis of beliefs in rights, as developed by Joshua Greene. His work is one of the sources of recent interest in debunking arguments. Together with other psychologists, he developed a dual-process model of moral reasoning. ${ }^{3}$ Drawing on features of this model, Greene also advanced ethical arguments. Best known and most controversial is his attack on deontology based on his finding that deontological reasoning involves emotional brain mechanisms. ${ }^{4}$ This argument has generated, and continues to generate, heated debates. ${ }^{5}$ Related but lesser known is Greene's attack on rights.

(Jussi Suikkanen \& Antti Kauppinen eds., 2019); Markus Christen, Empirically Informed Ethics: Morality Between Facts and Norms (2013).

2. Debunking should be disambiguated from defeasibility, which has received attention from legal scholars. Cf. Giovanni Sartor, Defeasibility in Law, in Handbook of Legal Reasoning and ARgumentation 315 (Giorgio Bongiovanni et al. eds., 2018). Both relate to the fact that legal reasoning is incomplete and provisional. Debates about defeasible reasoning concern logical problems of premises and deductions in provisional and normative arguments; debunking concerns epistemic questions.

3. Fiery Cushman, Liane Young \& Joshua D. Greene, Our Multi-System Moral Psychology: Towards a Consensus View, in The Oxford Handbook of Moral Psychology 47 (2010); Joshua D. Greene, Beyond Point-and-Shoot Morality: Why Cognitive (Neuro)Science Matters for Ethics, 124 Eтнісs 695 (2014); Joseph M. Paxton, Leo Ungar \& Joshua D. Greene, Reflection and Reasoning in Moral Judgment, 36 Cognitive Sci. 163 (2012); Dual-Process Theories in Moral Psychology (Cordula Brand ed., 2016).

4. Greene, supra note 3; Joshua Greene, The Secret Joke of Kant's Soul, in Moral Psychology 35 (Sinnott-Armstrong ed., 2008); Joshua D. Greene, An fMRI Investigation of Emotional Engagement in Moral Judgment, 293 SCIENCE 2195 (2001).

5. Selim Berker, The Normative Insignificance of Neuroscience, 37 PhiL. \& Pub. Afrs. 293 (2009); Matthew Liao, Neuroscience and Ethics: Assessing Greene's Epistemic Debunking Argument Against Deontology, 64 Experimental Psych. 82 (2017); Guy Kahane, On the Wrong Track: Process and Content in Moral Psychology, 27 Mind \& Language 519 (2012); Norbert Paulo, In Search of Greene's Argument, 31 Utilitas 38 (2018); F. M. Kamm, Neuroscience and Moral Reasoning: A Note on Recent Research, 37 Phil. \& Pub. Affs. 330 (2009); Jonathon Hricko \& Derek Leben, 
He claims that at the psychological level, rights are rationalizations of moral intuitions. ${ }^{6}$ (More precisely, one should, and I will henceforth, speak about beliefs in rights. The claim is absurd in an ontological sense. In other words, Greene claims that when people form the belief that a right to X exists, they rationalize an intuition about $\mathrm{X}$.) At the normative level, he argues that rationalized intuitions are an untrustworthy or unreliable source for ethical (and we can add, legal) beliefs. As a consequence, beliefs so formed are not warranted. They should be discounted or debunked.

So far, Greene's argument against rights has only provoked one scathing reply from a legal scholar. ${ }^{7}$ And indeed, it is formulated unsystematically and betrays a narrow understanding of rights, which let it appear as an easy target for criticism. However, by rejecting it too quickly, one runs the risk of missing the intriguing insight it has to offer. The following thus reconsiders Greene's argument in a charitable interdisciplinary spirit. In particular, his noteworthy views about the psychology of rights shall be reconstructed as they may well be of interest to legal scholars beyond the purposes of this paper. His normative argument, however, will not be faithfully reconstructed. Instead, a novel argument geared toward the law and beliefs in human rights in particular shall be developed on the basis of his psychological model. It suggests that some forms of reasoning about rights can be defective, so that conclusions and beliefs generated by them are undermined. This allows undermining beliefs about legal matters by resorting to psychological facts, rather than arguing on the merits. Demonstrating the possibility of such an argument and establishing the proof of concept that psychological facts about reasoning can be brought to bear on legal arguments is the main aim of this paper. It should motivate legal theory to examine further potential implications of moral psychology as well as prospects of debunking arguments given the specific methodological and substantive commitments of the law. Greene's claims are a witty invitation to do that.

The first section of this article briefly introduces the idea and the structure of philosophical debunking arguments. The second section presents Greene's argument against rights, primarily its empirical premises and presuppositions about intuitive and rationalizing reasoning. This provides the basis for developing a legal debunking argument in the third section. Its normative premises are derived from two conditions of justifying human rights: The adequate justifications of rights vis-à-vis duty-bearers and the general applicability (universalizability) of human rights to a large number

In Defense of Best-Explanation Debunking Arguments in Moral Philosophy, 9 Rev. PHIL. \& Psych. 143 (2018).

6. He develops the argument against rights in Chapter 13 of his popular science book, JoshUA D. Greene, Moral Tribes: Emotion, Reason, and the Gap Between Us and Them (2013).

7. Matthias Mahlmann, Mind and Rights: Neuroscience, Philosophy, and the Foundations of Legal Justice, in Law, REASOn, AND Emotion 80 (M.N.S. Sellers ed., 2017). 
of cases. Intuitive and rationalizing reasoning, so the argument goes, cannot meet these conditions in a satisfactory manner, so that beliefs resulting from such reasoning are debunkable. Although the scope of this argument is narrower than the one proposed by Greene, it is a valid and sound argument that allows debunking beliefs in rights. The fourth section sketches how the argument may inform and motivate further psychological research. While it is hard to ascertain whether any human right ultimately will be debunked, the normative perspective on the psychology of legal reasoning can certainly be used to make legal thinking better.

\section{INTRODUCING PROCESS DEBUNKING ARGUMENTS IN ETHICS}

Debunking arguments come in various types. ${ }^{8}$ Of present interest are epistemic forms. They draw on the fact that beliefs are and should be held with different levels of confidence. We more strongly believe in the truth, or correctness, of some propositions than in the truth of others; we are sometimes certain and inclined to disbelieve at other times. The degree of confidence in a belief depends, among other things, on the available evidence and the way in which the belief was formed. Confidence should change, in rational thinkers, in light of new information. Debunking arguments aim at lowering confidence in the correctness of a belief, its epistemic credence, usually to an extent that holding the belief is no longer justified..$^{9}$ Process debunking arguments draw on defects in the processes of forming beliefs by showing that they are not reliable in generating correct results because they are prone to some form of error. ${ }^{10}$ As a consequence, confidence in so formed beliefs is undermined. Importantly, however, debunking does not falsify or refute the proposition. In legal terms, one may say that debunking is not an argument on the merits. Yet, it is not a classic procedural argument either. It is about the procedure of forming beliefs in the mind. Its standards do not stem from legal rules of procedure, but from rules of epistemic rationality.

8. The most comprehensive treatment of debunking argument so far is SAUER, supra note 1.

9. Of course, this requires thresholds for justifications of beliefs, and they can diverge depending on the type of belief and alternatives to the belief. I will not get into these matters. For an introduction, see Degrees of Belief (Franz Huber \& Christoph Schmidt-Petri eds., 2009). Moreover, debunking arguments only show that reaching a belief through a specific way or route (e.g., a reasoning process) is insufficient to justify the belief, because it is, e.g., elliptical or erroneous. Debunking does not rule out these defects being overcome. Debunking is thus provisional. To the law, this approach is familiar with respect to fact-finding and evidence, for which it stipulates standards of beliefs, such as "beyond reasonable doubts" or "balance of probabilities." It is just that the objects of beliefs of present interest are norms not facts (concerning the burden of persuasion about points of law).

10. The term is borrowed from Nichols, supra note 1. 
Debunking arguments are thus situated between classic legal categories of procedure and substance; they are epistemic, drawing on procedure but aiming at substance. A successful debunking argument undermines beliefs without disproving them or providing better alternatives.

Debunking arguments that draw on the evolutionary genesis of beliefs have a long history and have seen renewed interest recently. Darwin famously contended that if humans were raised under the environmental conditions of hive bees, they would certainly hold that unmarried females should kill their brothers and mothers should kill their daughters. ${ }^{11}$ The suggestion is that moral beliefs shaped by evolution will express attitudes favorable to survival, but not necessarily to moral truth. Beliefs depend on contingent environmental circumstances in which they are formed. ${ }^{12}$ And if the best explanation for why a person holds a belief is not its truth or correctness, but some other explanation (survival-value), confidence in its truth or correctness is not warranted. ${ }^{13}$

Instead of evolutionary genesis, debunking arguments may address more proximate processes of belief formation. Here is an example: suppose your trustworthy friend $\mathrm{F}$ reports having witnessed a mystical star last night. After a seemingly endless firework of shooting stars, a dazzling bright and diamond-shaped star quickly traversed through the sky. Should you believe him? As there is no means to directly access a past event, we have to rely on other sources. Among the best ways to find out whether there indeed was an extraordinary stellar constellation is to consult astronomers. With models and calculations, they can simulate yesterday's night sky. Their answer may have shortcomings, but by and large, they will provide a reliable estimate. We would be justified in believing their report, and given their track record, even with high confidence, so that we can use it to assess F's report. However, there might be alternative ways to evaluate it, to which we would have to resort if there were neither astronomy nor astronomers, or if there were persistent disagreement among them. Suppose it becomes known that $\mathrm{F}$ was under the influence of a psychedelic drug that often distorts perception. This fact may suffice to undermine F's belief because it was formed based on a perception generated by processes known

11. Charles Darwin, The Descent of Man, and Selection in Relation to Sex (1981), at 73.

12. The evolutionary heritage may cast doubts on metaethical positions such as moral realism (the view that there are mind-independent moral truths). An influential argument is Sharon Street, A Darwinian Dilemma for Realist Theories of Value, 127 PhIL. STud. 109 (2006); for different views see Richard Joyce, The Evolution of Morality, Life and Mind (2006); Kahane, supra note 1; Guy Kahane, Evolution and Impartiality, 124 Eтнісs 327 (2014); William J. FitzPatrick, Human Altruism, Evolution and Moral Philosophy, 4 Royal Soc'y Open Sci. 170441 (2017); Russ Schafer Landau, Evolutionary Debunking, Moral Realism and Moral Knowledge, 7 J. Eтнісs \& Soc. Phil. 1 (2013). But evolutionary genesis may also call normative beliefs into question (e.g., that the moral duty to save a person in one's vicinity is stronger than the moral duty to rescue someone in a faraway place; see Peter Singer, Famine, Affluence, and Morality, 1 Phil. \& Pub. Afrs. 229 (1972)).

13. Nichols, supra note 1; Hricko \& Leben, supra note 5. 
to cause errors of a certain type. By extension, believing F's report is not warranted. The structure of the argument runs like this:

(i) Belief B is formed through process $\mathrm{P}$ [empirical premise].

(ii) Process $\mathrm{P}$ is defective (e.g., it regularly generates false beliefs as it distorts perception or suffers from other epistemic weaknesses) [normative premise 1].

(iii) Considering a belief generated by defective processes to be true is not justified [normative premise 2].

(conclusion) Considering B to be true is not justified.

The argument is valid; the conclusion can be inferred from premises (i)(iii). One may argue about thresholds of justification and defectiveness, or about whether believing something necessarily entails considering it to be true, but these matters do not affect the main argumentative structure of the syllogism. Applied to the star example, considering F's report to be true is not justified. Note, however, that it might be true. Whether there was an extraordinary star is still open, we are just not justified in believing that there was. This is the basic structure of process debunking arguments.

Moving from beliefs about facts of the world to normative beliefs, one may wonder whether debunking arguments are applicable. The main challenge is to formulate a plausible normative premise in the place of (ii). Because objects of ethical beliefs might not exist in the same way as stars do, finding out whether ethical beliefs are correct-and which formative processes are defective-may differ from finding out whether facts about the world are correct. Here, we touch on a deeply controversial metaethical question, the ontological status of "ethical facts." Are they out there in the world, independent from human thinking (realism), or are they humanmade (antirealism) $?^{14}$ In the latter case, without independent standards, there is no procedure in ethics that allows testing the outcomes of beliefforming processes against reality analogous to the testing of models of astronomers. Ethical debunking arguments have to deal with this challenge ("calibration problem"). A common strategy is identifying belief-forming processes that typically go astray because they run afoul of fixed methodological directives, are deceptive, or confer unsupported degrees of confidence. Such processes are defective according to a great range of ethical theories. Even if we disagree about the criteria of good ethical judgment, we may agree that throwing dice is usually not among them. Such typical shortcomings allow formulating a normative premise akin to (ii). So much for ethics. The question further addressed in the third section is whether and how such an argumentative strategy can be applied to the law. To

14. For a metaethical realist view, see Russ Shafer-Landau, Moral Realism: A Defence (2003); for antirealism, see Richard Joyce, Moral Anti-Realism, in Stanford Encyclopedia of Philosophy (Edward N. Zalta ed., 2016). 
anticipate: confidence in the belief that a specific human right to $\mathrm{X}$ is justified may, just like confidence in other beliefs, be strengthened or weakened in light of the processes that bring it about. And while there is no fixed method for arguments about human rights, there are normative standards for good and defective legal reasoning that are derivable from legal methodology and argumentation theory.

\section{GREENE'S ARGUMENT AGAINST RIGHTS}

Against this backdrop, we can turn to Greene's argument against rights, which he lays out in several loosely connected passages in his book Moral Tribes. It is not a rigorous deduction, more a set of remarks revolving around the same point: ${ }^{15}$ rights are rationalizations of untrustworthy psychological intuitions and should therefore be discarded. The argument might be summed up like this:

(gp1): Arguments in favor of rights are rationalizations of intuitions [empirical premise].

(gp2): Rationalizing intuitions is a defective process for reaching correct beliefs [normative premise 1].

(gp3): Beliefs resulting from defective processes should be discarded [normative premise 2].

(conclusion) Beliefs resulting from arguments in favor of rights result from defective processes and should be discarded.

The argument is valid; the question is whether it is sound. ${ }^{16}$

\section{A. Rights and Interests}

Let us look at the empirical premise-are beliefs in rights rationalizations of intuitions, and what does this mean more precisely? To take off some steam already at this stage, it is useful to qualify the premise. Very likely, some beliefs are formed in this way, but perhaps not all of them are. The argument should thus be restricted to the former (more about this later). The modified premise reads:

$\left(\mathrm{gp} 1^{*}\right)$ : Some arguments in favor of rights are rationalizations of intuitions.

15. In fact, it is not entirely clear whether he conceives of it as a standalone argument against rights as normative entities, or as a consequence of his general attack on deontology.

16. One cannot speak about Greene's work without noting the influential criticism of it by Berker (supra note 5). Berker's criticism showed that neuroscientific findings played a much lesser role in Greene's argument than originally appeared to be the case. I concur with much of Berker's criticism. However, it does not touch the present debunking argument, which does not rely on neuroscience either. Neuroscience is relevant only insofar as it sheds light on empirical matters such as the dual-process model of reasoning, or whether particular legal beliefs were indeed formed through IR-reasoning. The present argument is thus compatible with Berker's critique. 
Moreover, Greene is a consequentialist. He understands interests but has problems with rights, insofar as they oppose consequentialist interest maximation (he disregards, e.g., rule-consequentialist justification of rights). ${ }^{17}$ The kinds of rights attacked by his arguments are those that cannot be justified on consequentialist grounds; let us call them "nonconsequentialist rights." His claim is thus more precisely stated in this way:

(gp1**): Some arguments in favor of nonconsequentialist rights are rationalizations of intuitions.

Greene's argument touches on a key conflict, familiar to every legal system, between interests and rights. A textbook example is torturing the terrorist in ticking bomb scenarios: interest maximation speaks in favor of doing so, the right against torture against. This power of rights to override or "trump" consequentialist considerations, their "nonnegotiable" character, is the target of Greene's argument. He wonders where this special normative status of rights comes from. A view from within the law may reply that this is the logic of legal systems; rights (regularly) prevail over interests. But Greene is interested in whether this also can be justified from outside the law, and he provides a psychological story for the belief in the special status of rights that casts doubt on it. This psychological explanation is fascinating and merits attention by legal scholars.

\section{B. Similarities in the Structures of Minds and Normative Systems}

The pivotal point of his psychological explanation is that beliefs affirming rights arise from other causal processes than beliefs affirming interest maximation do. In other words, the differences between views favoring flexible and balanceable interests and those favoring categorical and schematic rights correspond to two distinct psychological mechanisms. ${ }^{18}$ Normative questions are computed by two psychological systems that provide different outputs. Mechanisms of these systems have different properties, e.g., they are sensitive to different types of information and typically give rise to different types of judgments. One tends to judge in characteristically deontological ways—and thus supports rights—whereas the other tends to judge in characteristically consequentialist ways-and aggregates interests, without accommodating a special authority of rights. Herewith, Greene provides the first psychological explanation for the widely observable fact that normative systems often have two different and sometimes conflicting entities,

17. As currently understood in law, human rights indeed have nonconsequentialist elements, i.e., they imply positions that cannot be overridden by considerations of public welfare (or costs). This is true not only for absolute rights, but also for standard human rights. They might be weighed against other human rights or pressing interests, but regularly prevail over other considerations.

18. This is reconstructed from several of Greene's writings, particularly GREENE, supra note 6, and Greene, supra note 3. 
interests and rights. Furthermore, he argues that the way they relate to one another has a psychological ground: outputs of some psychological mechanisms cannot easily be overridden by other mechanisms. Therefore, it seems to thinkers that these outputs should be accorded special authority. This is the alleged psychological background to the view that there are special normative entities called "rights."

To illustrate, suppose a psychological mechanism computes the consequence of potential actions $\mathrm{A}$ and $\mathrm{B}$ in terms of interest maximation and comes to the conclusion that the overall gains through $\mathrm{A}$ exceed those through $\mathrm{B}$, and that A should thus be chosen. But despite this, the reasoner is psychologically not sure about A'ing; something is resisting the conclusion to A, as with torturing a terrorist. In Greene's model, this conflict arises from different competing mechanisms; the outputs of one (do not torture) are not easily overridden by the outputs of the other (interests increase overall) and sometimes may not be overridden at all. To the reasoner, it appears that better reasons speak in favor of those outputs that cannot be outweighed by consequentialist interest maximation. This experience gives rise to the idea that there must be nonoverridable entities-rights.

More broadly speaking, Greene identifies structural similarities between the psychology of decision-making and normative systems emphasizing rights or interests. Contents of normative systems-the apparent existence of two different entities-as well as the rivalry between the two large families of normative ethics—consequentialism and deontology—seem to mirror features of the dual cognitive system. If this claim proves correct, it is intriguing and has potentially far-ranging implications for metaethics, normative ethics, and the law, as it would provide psychological explanations for features of normative systems as well as for conflicts that are traditionally conceived as substantive disagreements.

\section{Dual-Process Model of Moral Reasoning}

Greene's empirical claim may appear bold. It has been tested by the familiar Trolley-type dilemmas, but not, as far as I can see, with respect to other conflicts between rights and interests or different types of rights. It enjoys some plausibility as it is derived from a broader model of moral reasoning that is well established. ${ }^{19}$ The dual-process model of moral reasoning has received support from various disciplines and has been popularized among others by Daniel Kahneman's bestselling contrast between "thinking fast and thinking slow." ${ }^{20}$ The rough idea is that two systems with different powers and abilities can be distinguished, System 1 and System 2. The former is evolutionarily older and works fast and frugally, mostly outside of

19. One of the main criticisms is that the different mechanisms do not neatly track the different normative positions, e.g., Kahane, supra note 5.

20. Daniel Kahneman \& Shane Frederick, A Model of Heuristic Judgment, in The Cambridge Handbook of Thinking and Reasoning 267 (Keith J. Holyoak \& Robert B. Morrison eds., 2005); Daniel Kahneman, Thinking, Fast and Slow (2011). 
awareness; its mechanisms respond quickly and on the basis of limited information and it is automatic, associative, and reliant on heuristics. Its computing powers are severely limited, but it allows for a lot of parallel processing. It can only draw on implicit knowledge, and its outputs are largely independent of general intelligence. This is the intuitive system. By contrast, System 2 is the analytical system; it operates slowly, has a "low bandwidth," and requires effort. Its operations are often conscious. Typical elements of normative reasoning such as counterfactual, rule-based, and deductive thinking, comparisons, and weighing of reasons are System 2 operations. System 2 is also necessary for "hypothetical thinking, which requires imaginations of possibilities and mental simulations and the ability to decouple suppositions from actual beliefs." ${ }^{21}$ It has access to memory and its outputs depend on general intelligence. Whereas System 1 is activated by default, System 2 only becomes activated for special purposes. This is concededly a coarse-grained contradistinction, but it is widely supported and suffices for present purposes.

According to the dual-process model, normative judgment is a two-phase process. Information about a case is first processed by System 1, which provides an intuitive judgment as an output, an intuition. This output may then be further processed by System 2. The particular twist that Greene and colleagues like Jonathan Haidt give to this picture is the claim that in many cases, System 2 operations do not critically scrutinize the intuition, but rather justify and elaborate on it. Roughly speaking, System 1 provides the result and System 2 the justification. Let us call this type of reasoning intuition-rationalization or IR-reasoning. As Greene and Haidt write:

[Moral] judgment is much like aesthetic judgment: we see an action or hear a story and we have an instant feeling of approval or disapproval. These feelings are best thought of as affect-laden intuitions, as they appear suddenly and effortlessly in consciousness, with an affective valence (good or bad), but without any feeling of having gone through any steps of searching, weighing evidence or inferring a conclusion. These intuitions . . . are shaped by natural selection, as well as by cultural forces. People certainly do engage in moral reasoning, but, as suggested by studies of informal reasoning, these processes are typically one-sided efforts in support of pre-ordained conclusions. ${ }^{22}$

In this sense, many normative judgments are rationalizations of intuitions; and to Greene, those that generate beliefs in rights are among them. As

21. For an introduction to dual-process models and their development through the history of ideas, see Jonathan Evans \& Keith Frankish, In Two Minds (2009) (quotation at 17); cf. Kahneman, supra note 20; Jonathan Evans, Dual-Processing Accounts of Reasoning, Judgment, and Social Cognition, 59 Ann. Rev. Psych. 255 (2008); Vinod Goel, Anatomy of Deductive Reasoning, 11 Trends Cognitive Scis. 435 (2007); Hanno Sauer, Moral Thinking, Fast and SLOW (2018).

22. Joshua Greene \& Jonathan Haidt, How (and Where) Does Moral Judgment Work?, 6 Trends Cognitive Scis. 517 (2002). 
an example, consider the moment you hear about a gross injustice (e.g., killing of innocent people, rape). This immediately evokes a condemnatory emotional reaction, and this reaction comes prior to a conscious normative evaluation of the facts of the case. The condemnation is noninferential, it does not result from consciously consulting and applying principles of justice. In fact, the reaction is too quick for all the facts to be duly processed. It is more like a moral reflex (in an untechnical sense). Phenomenologically, the operations giving rise to the intuition are opaque; they are introspectively inaccessible but they must have taken place, as intuitions are neither random nor even surprising. So although we do not introspectively know the rules by which these mechanisms evoke intuitions, we must assume that they follow rules. Moreover, and importantly, although the initial reaction is driven by an intuitive apprehension and processing of the facts, once it has been formed, it provides a view on the matter, and, depending on its strength, often a firm one. Studies show that in the great majority of cases, people defend the position they intuitively hold. ${ }^{23}$ This position seems to them to be motivated by good reasons rather than driven by a spontaneous, noninferential intuition-even though that is where it originated. In this way, spirited arguments in favor of a cause may, on a closer look, turn out to be, in Greene's words, "intuition chasing." ${ }^{24}$ We often take our intuition as a firm anchor of values to be defended, rather than the output of a flimsy process to be treated with caution and necessitating reflection.

Our observations so far have concerned moral reasoning. Do they also apply to legal reasoning? This is partly an empirical and partly a theoretical question. With respect to the latter, I wish to circumvent familiar quarrels over the general separability of law and morality by drawing attention to the fact that in the present context of the justification of human rights, positive law has to be transcended. With respect to the former, the dual-process model is closer to factual legal decision-making than it may appear. Intuition inputs into legal reasoning such as the "judicial hunch" are proverbial. ${ }^{25}$ One may wonder if it is possible to not have intuitions about legal cases, as System 1 processes incoming information about them. The hunch is followed by a phase of more thorough deliberation. This is reflected in the methodological distinction between the context of discovery, where legal judgments are formed on associative and heuristics routes, and the context of justification, where a decision is more systematically and methodologically tested and justified. Empirical studies with

23. Jonathan Haidt, The Emotional Dog and Its Rational Tail: A Social Intuitionist Approach to Moral Judgment, 108 Psych. Rev. 814 (2001); Matthew L. Stanley, Ashley Dougherty, Brenda Yang, Paul Henne \& Felipe De Brigard, Reasons Probably Won't Change Your Mind: The Role of Reasons in Revising Moral Decisions, 147 J. Experimental Psych. 962 (2018).

24. Greene, supra note 3, at 718.

25. Locus classicus Joseph C. Hutcheson, Jr., The Judgment Intuitive: The Function of the "Hunch" in Judicial Decision, 14 Cornell L. Rev. 274 (1929). 
judges have inspired dual-process accounts of judging such as the "intuition-override" model by prominent scholars. It posits that "judges generally make intuitive decisions but sometimes override their intuition with deliberation." ${ }^{26}$ The two-phase model that Greene draws on is thus no stranger to legal reasoning. ${ }^{27}$

\section{Post hoc Rationalization}

However, one may be inclined to emphasize that the essence of legal reasoning is not explicating intuitions, but refining and weighing reasonssubsequent System 2 operations. Indeed, more must be said about this second phase. After System 1 has formed an intuition, System 2 can either remain idle, confirm the intuition, or override it. Greene and Haidt contend that System 2 often post hoc rationalizes System 1 intuitions, confirming rather than scrutinizing them. Greene claims that this is regularly the case with respect to affirmative beliefs about rights, but not, by contrast, consequentialist beliefs; the former but not the latter allegedly result from rationalization.

What is post hoc rationalization more precisely? Psychology does not provide a fixed definition. For present purposes, we may adopt the formulation suggested by philosophers Schwitzgebel and Ellis:

[R]ationalization is post-hoc reasoning toward a favored conclusion, where both the preference for the conclusion and the search for justifications are shaped by some epistemically non-probative distorting factor that isn't explicitly appealed to in those justifications. ${ }^{28}$

It is one-sided reasoning in support of a favored outcome, closely related to phenomena such as motivated cognition, myside bias, confirmation bias, or reason confabulation. What role do reasons play? During rationalizing

26. Chris Guthrie, Jeffrey Rachlinski \& Andrew J. Wistrich, Blinking on the Bench: How Judges Decide Cases, 93 Cornell L. Rev. 1, 3 (2007). Of course, this model and Greene's work have common sources in psychological findings about decision making. But, more generally, it is unlikely that legal reasoning will not recruit general mental mechanisms for decision-making. There is no "legal mind" separate from mechanisms used for other purposes. Legal reasoning may require special skills, and legal training may strengthen them, but they all run on the same general hardware and psychological framework. For one of the first fMRI studies on legal reasoning, see Stephan Schleim, Tade Spranger, Susanne Erk \& Henrik Walter, From Moral to Legal Judgment: The Influence of Normative Context in Lawyers and Other Academics, 6 Soc. Cognitive \& Affective Neuroscience 48 (2011).

27. Nonetheless, this is surely a simplification and not a general statement about judicial reasoning. There is likely no uniform theory, as decision types and procedures vary, and deliberation over (complex) cases is long and windy. Moreover, the intricate nature of collective deliberations has to be accounted for in an ecologically valid model of judicial decisionmaking. So far, such a model is outstanding. But present purposes do not require such a comprehensive model. The aim is showing that under a plausible model of judicial decision-making with some empirical backing-perhaps the best currently on the table-psychology can be brought to bear on normative questions.

28. Eric Schwitzgebel \& Jonathan Ellis, Rationalization in Moral and Philosophical Thought, in Moral Inferences 172 (Jean-François Bonnefon \& Bastien Trémolière eds., 2017). 
deliberation, people come up with reasons for the rationalized position and convince themselves that those reasons are the better, more weighty ones. Subsequently, they will appeal to those reasons to justify their belief. However, the antecedent searching for reasons and their weighing was skewed from the beginning, and counterarguments were not duly accommodated. Reasons are thus not causally inert; they play a supportive role for the belief, but it was formed prior to and without those reasons. Importantly, rationalization often operates outside of the awareness of reasoners, under an "illusion of objectivity." ${ }^{29}$ It can affect the evaluation of evidence, the weighing of arguments, the choice of a method of interpretation, etc.

What appears to be at the heart of philosophical or legal debate, the argumentative back-and-forth, the exchange of reasons, criticism and rebuttal, might be carried out in good faith, in great depth and sophistication, and seem open to thinkers. However, it frequently reaches the conclusion that was suggested by the initial intuition. ${ }^{30}$ The appearance of open-ended reasoning is then mistaken; deceptive, it arises from the limits of introspection. Due to these limits, the absence of a motivation of thinkers to reason one-sidedly or their unawareness of doing so does not indicate the contrary. Moreover, rationalization is not a matter of intelligence since people who score higher on cognitive reflection tests show more motivated reasoning. ${ }^{31}$ Because of its deceptive aspect, self-reports dismissive about rationalization are not very reliable; behavioral evidence is better. The question is how often people change their minds in the counterintuitive direction. Starting with oneself, one may wonder what happens when an intuitively formed view on a matter is challenged by someone else. According to Greene and Haidt, people are strongly inclined to defend their position and search for arguments in that direction, but not to the contrary. A range of studies showing that post hoc rationalization is much more common than it appears to thinkers supports this view-in fact, rationalization seems pervasive. ${ }^{32}$ Once one becomes aware of the phenomenon, one begins to find it in many places, from friends to family, school boards to parliamentary debates.

Rationalization also abounds in law. One-sided arguments in favor of a conclusion are well known to everyone in the legal field as they are the standard form of reasoning in litigation. This is harmless insofar as everyone is

29. Avani Mehta Sood, Motivated Cognition in Legal Judgments-An Analytic Review, 9 Ann. Rev. L. \& Soc. ScI. 307 (2013).

30. Haidt, supra note 23; Stanley et al., supra note 23.

31. Dan M. Kahan, Ideology, Motivated Reasoning, and Cognitive Reflection: An Experimental Study, 8 Judgment \& Decision Making 407 (2012).

32. Chandra Sekhar Sripada \& Stephen Stich, A Framework for the Psychology of Norms, in 2 InNateness and the Structure of the Mind 280 (2006); Haidt, supra note 23; Charles S. Taber, Damon Cann \& Simona Kucsova, The Motivated Processing of Political Arguments, 31 Pol. Behav. 137 (2009); Dan M. Kahan, supra note 31, at 18; Hugo Mercier \& Dan Sperber, Why Do Humans Reason? Arguments for an Argumentative Theory, 34 BeHAv. \& BRAIN ScIs. 57 (2011). 
aware of the roles people play. But studies also demonstrate nonconscious forms of rationalization in legal reasoning. ${ }^{33}$ According to Greene, prorights arguments are typically rationalizations. He infers this from his Trolley-dilemma studies. Without questioning this research, I wish to register some doubts about the generalizability of those findings. I suppose that Greene-and for that matter Haidt-underestimates the effectiveness of deliberate conscious reasoning. Anyone who has deliberated over a hard case has had the experience of intuitions swinging back and forth, of testing, rejecting, and resurrecting judgments. Furthermore, rationalization is, to some degree, limited by the law. Contrary to crude Legal Realist claims, legal materials substantively constrain the scope of possible judgments and, thereby, possible rationalization. Nonetheless, such doubts about the extent of rationalization are not relevant for the present inquiry insofar as it concerns arguments within the range of the reasonable. In this range, good reasons speak for either side. Although rationalization has limits, there are enough interesting cases inside those limits. In line with psychological research, ${ }^{34}$ one should presumably follow the cautious advice by Schwitzgebel and Ellis: "It is untenable . . . for a philosopher or scientist to maintain with confidence that his or her moral or philosophical reasoning is not substantially impacted by rationalization." 35 Fortunately, the empirical question about the prevalence of IR-reasoning can be bracketed for the following argument. It suffices to acknowledge that some beliefs in rights are formed in this way and to restrict it to them (as in $g \mathrm{p} 1^{* *}$ ).

\section{E. Greene's Normative Argument}

Let us turn to the normative argument. Greene suggests that beliefs formed through IR-reasoning should be dismissed because the process is defective. He provides several normative arguments for the unreliability of IR-reasoning, which have provoked many responses. I will reconstruct only some parts relevant for present purposes. To begin, it might be helpful to split the argument and formulate two distinct normative premises:

(gp2a) Intuitions are defective because they are not good or valid sources for correct normative beliefs;

(gp2b) Post hoc rationalizations are defective. Although they seem to provide reasons for belief, they do not properly acknowledge counterarguments. They raise confidence in the correctness of a belief to an unwarranted degree (overconfidence).

33. For an overview of studies on motivated cognition in the legal realm, see Sood, supra note 29; Dan M. Kahan, Foreword: Neutral Principles, Motivated Cognition, and Some Problems for Constitutional Law, 125 Harv. L. Rev. 1 (2011); Eileen Braman, Law, Politics, \& Perception: How Policy Preferences Influence Legal Reasoning (2009).

34. Sood, supra note 29; John F. Irwin \& Daniel L. Real, Unconscious Influences on Judicial Decision-Making: The Illusion of Objectivity, 42 McGeorge L. REv. 1 (2010).

35. Schwitzgebel \& Ellis, supra note 28, at 180. 
In conjunction, post hoc rationalization of intuitions is a defective process. Confidence in the correctness of a belief formed through IR-reasoning is not warranted.

\section{Defects of Post hoc Rationalization}

Are these premises sound? Starting with the second, what is wrong with post hoc rationalization? Let us call the intuitively formed belief $\mathrm{B}$. It is held with some confidence $\mathrm{C}$ that lies on a spectrum (say from 0 to 1 ). In rational belief formations, arguments pro and con B would be sought and pondered, and $\mathrm{C}$ would be altered (lowered or increased) in light of the quality of the arguments. If $\mathrm{B}$ can be sustained through a process of testing against counterarguments, $\mathrm{C}$ should increase; believing B is justified to a higher degree. It might of course still be defeated in the next round of argument. By contrast, post hoc rationalization of B means that reasons in its favor are invoked whereas opposing ones are downplayed or defused, with the outcome more or less fixed from the beginning. The fact that B is maintained through such a process does not indicate that the better reasons speak in its favor. Potentially defeating arguments were simply not duly taken into consideration. B apparently stood the test of counterargument, but this impression is mistaken; $\mathrm{C}$ should not increase. At best, rationalization may prove that $\mathrm{B}$ is not completely unfounded because some reasons in its favor can be invoked. But it falls short of showing that they are persuasive or preferable to alternatives. To the thinker, however, rationalization strengthens the belief, so that it becomes harder to reverse it in the future. This increase in confidence is epistemically not justified and leads to overconfidence. Post hoc rationalization is thus an epistemically defective process. As a remedy, $\mathrm{C}$ has to be reversed to the ex ante level. ${ }^{36}$ The second normative premise (gp2b) is sound.

\section{Defects of Moral Intuitions}

What about the first premise-are intuitions defective ${ }^{37}$ Let us first disentangle them from emotions. Intuitions are spontaneous, noninferential System 1 outputs. They can be caused or accompanied by emotions, and they may in turn cause emotions, but they are distinct from emotions. Emotions have different causal powers; they may, for instance, also affect nonintuitive System 2 reasoning. Emotions and intuitions should thus be

36. One may also look at rationalization through the lens of self-deception. Since it operates largely outside of awareness, it is not obvious to the reasoner that the result of her deliberations or the outcome of the weighing of arguments is fixed. The fact of self-deception is irritating and undermines trust, but it does so primarily in the self-relation of the rationalizer, not necessarily with respect to the belief. Perhaps, another debunking argument can be based on it. See Hricko \& Leben, supra note 5; Regina A. Rini, Why Moral Psychology Is Disturbing, 174 PhIL. STud. 1439 (2017).

37. It is necessary to distinguish between emotions and intuitions. Unfortunately, Greene uses both too loosely in his book (written for a popular audience). In the scientific debate, both should be separated (Greene would agree). 
kept apart. ${ }^{38}$ Normatively, one might argue in a traditional rationalist vein that emotional influence on belief formation or decision-making is per se a distortive factor. But in this generality, a rationalist position is not convincing. For instance, it seems that emotions do not always cloud judgment, but may also be guides to good decisions, as people with emotional deficits regularly make bad ones. ${ }^{39}$ However, I wish to leave aside the well-trodden controversies over emotivism, sentimentalism, and rationalism. The more interesting and fruitful target is intuitions.

Whether intuitions are unreliable for belief formation is a hotly debated question. As intuitions are noninferential, the question can be put in Sinnott-Armstrong's terms: Are people "adequately epistemically justified in holding some moral beliefs independently of whether those people are able to infer those moral beliefs from any other beliefs"? ${ }^{40}$ Two positions can be contrasted: the first considers intuitions similar to stereotypical and simple reflexes generating incoherent outputs. Consequently, people are not justified in holding any belief arising from them. The opposing view urges appreciation of the benefits of a flexible and adaptive intuitive system. ${ }^{41}$ Insofar as intuitions are amendable to learning, they may express considered judgments rather than inflexible or rigid responses. A good example is the "judicial hunch," the intuitive assessment of cases by experts. ${ }^{42}$ These intuitions are learned, acquired through training and experience. They therefore cannot be debunked for the reason that they are noninferential and nonreasoned. They result from earlier reasoning processes. ${ }^{43}$ However, other intuitions have a less fortunate genealogy because they are innate or because they arise from cultural, social, and other forces, but not from reasoning. It seems that there is no reason to trust in the correctness of those intuitions. They are of interest in the following.

38. It is also notoriously unclear whether emotions cause these outputs or are caused by them, and it is quite hard to test the causal order experimentally. Likely, there are no "straight arrows of causation" but rather feedback loops between intuitive processes and emotions. To simplify matters, the emotional aspect is left out in the following, as it does not seem to generate further distinct and novel normative questions.

39. That is, for example, the main insight of Damasio's somatic marker thesis. Antoine Bechara \& Antonio R. Damasio, The Somatic Marker Hypothesis: A Neural Theory of Economic Decision, 52 Games \& Econ. Behav. 336 (2005); cf. Jennifer S. Lerner, Ye Li, Piercarlo Valdesolo \& Karim Kassam, Emotion and Decision Making, 66 Ann. Rev. Psych. 799 (2015).

40. Walter Sinnott-Armstrong, Moral Intuitionism Meets Empirical Psychology, in Metaethics After Moore 339, 341 (Terry Horgan \& Mark Timmons eds., 2006); cf. Peter Singer, Ethics and Intuitions, $9 \mathrm{~J}$. Етнісs 331 (2005).

41. Gerd Gigerenzer \& Jurgen Rossbach, Gut Feelings: The Intelligence of the Unconscious (2008); Peter Railton, Moral Learning: Conceptual Foundations and Normative Relevance, 167 Cognition 172 (2017); Hanno Sauer, Moral Judgments as Educated Intuttions (2017); Cass R. Sunstein, Moral Heuristics and Moral Framing, 88 Minn. L. Rev. 1556 (2003). But see Joshua D. Greene, The Rat-a-Gorical Imperative: Moral Intuition and the Limits of Affective Learning, 167 Cognition 66 (2017).

42. See, e.g., Linda L. Berger, A Revised View of the Judicial Hunch, 10 Legal Comm. \& Rhetoric: JAWLD 1, 41 (2013).

43. For a more skeptical view on these intuition-rehabilitation positions, see Greene, supra note 41 . 
The main argument against intuitions in current debates concerns their susceptibility to morally irrelevant factors. ${ }^{44}$ Greene, for instance, acknowledges that intuitive responses are often helpful heuristics, but draws attention to the fact that they may also go astray, especially in situations that are novel or only superficially resemble familiar ones. Then intuitions easily "misfire." Moreover, studies show that moral intuitions are susceptible to a range of distorting and irrelevant factors, such as the cleanliness of the surrounding, smells, priming through unrelated anchors, framing, and order effects. Even expert intuitions are not immune to such influences. As a consequence, Greene suggests distrusting intuitions, ${ }^{45}$ a position shared by a several philosophers. ${ }^{46}$ However, even if we grant that some intuitions are susceptible to distorting factors, it does not follow that all intuitions are indeed swayed by them. There might be stable intuitions that are not influenced by irrelevant factors. With respect to them, the argument does not have further traction. The irrelevant factor argument thus does necessitate discarding every intuition. Therefore, (gp2a) is not sound in this generality. For the debunking argument to succeed, a more nuanced view showing why and which intuitions are unreliable is needed.

\section{DEBUNKING HUMAN RIGHTS}

\section{A. Toward a Legal Debunking Argument}

The worries that motivate Greene are still alive, but they have to be formulated differently. In the following, I wish to develop a debunking argument specific to IR-reasoning and the law, or, more precisely, a legal justification for a premise akin to (gp2). Since debunking arguments have not yet been applied to the law, some broader remarks about their applicability and differences from the ethics context are warranted. First, the nature, existence, and cognizability of correct ethical results is highly contested in metaethics, whereas a set of correct answers (that may contain one or several answers) can be assumed to exist in law. ${ }^{47}$ At least in theory, positive law and the methodology of a particular legal system determine the process through which correct answers can be found. In other words, the calibration problem is solvable in law, even though it may require enormous (Herculean) efforts in practice. Second, the situation in the law is peculiar as it traditionally draws distinctions between substance and procedure, as well as between questions of law and questions of fact. With respect to the latter, something

44. Greene, supra note 3.

45. Greene suggests that instead of relying on intuitions, we should use System 2 processing to wrest "moral philosophy away from the automatic settings, away from the limitations of our biological and cultural histories, and turn ... it over ... to the brain's general-purpose problem-solving system." GreEne, supra note 6, at 312.

46. Singer, supra note 40.

47. I wish to remain uncommitted on Dworkin's single right answer thesis but will speak in the singular in the following. Nothing in the argument hinges on it. 
like a legal epistemology, shaped primarily through procedural rules, already exists. The rationale of many procedural rules is securing truthful fact-finding, and the violation of some of them may give grounds to appeal (or to some other challenge to a decision). The consequences that legal systems attach to violations of procedural rules may be considered a form of epistemological debunking: because the process by which a judgment has been reached was defective, it does not stand and has to be reviewed; this is the logic of epistemic debunking. However, third, legal appeals often require additional argument on the merits; a procedural failure or epistemic debunking alone may not suffice to overturn a decision. Fourth, many procedural rules also pursue aims of procedural justice. Violating them constitutes an independent wrong, unrelated to, and not indicative of, a wrong substantive outcome. This is unlike epistemic debunking. Not every procedural violation thus indicates an epistemic defect.

Fifth, a key difference between procedural challenges to legal decisions and epistemic debunking is that the latter is not concerned with finding facts, but with correct normative answers. The main question is whether debunking arguments may make a difference in this respect, whether they add something interesting and insightful for assessing substantive legal decisions. ${ }^{48}$ I wish to suggest that they do, but hasten to add that debunking is pointless when the correct substantive legal answer is easily found. Consulting it directly is preferable. Debunking becomes relevant when the correct answer is unclear, or difficult to determine, for the familiar reasons: open textures, indeterminacy, values, principles, deep disagreement. In these instances, beliefs of decision-makers (judges) about correct results remain tentative, open to further questioning or counterargument. Then, lowering confidence in beliefs becomes relevant, especially so if judgments depend on a confidence threshold (e.g., judges have to be convinced with reasonable certainty about a point of law). Lowering confidence may entail that thresholds are not met.

One area of application is distortive influences on judgments that are not expressed in written opinions. As a consequence, no error that would give ground for review can be found in the materials. Implicit biases are a good example. If it can be shown that the reasoning of a decision-maker in a concrete case is implicitly biased, the judgment should be debunkable, although biases are not visibly manifested in the written opinion. Biases remain "behind the text," invisible even to the reasoner (they are implicit). They may nonetheless influence outcomes, for instance, by subtly altering interpretations of vague concepts. A biased reasoning process is epistemically defective. Showing the presence of bias should arguably suffice to justify a review of the decision. Insofar as traditional remedies fail to capture

48. If debunking arguments are applicable and interesting, they might motivate reform of procedural rules. 
such psychological influences, a novel legal remedy might need to be introduced. ${ }^{49}$ This is the logic of debunking.

A related example is studies of the "hungry judge" type. Decisions of a parole board were apparently influenced by the time of the judges' last meal, as in the famous Realist trope that "justice is what the judge ate for breakfast." ${ }^{50}$ Confounding factors of this kind are typically not visible in judgments; they do not appear in the text. The individual decisions seem to fall within the range of the permissible; they are not visibly flawed. But patterns in hundreds of decisions suggest that they were nonetheless affected by some distortive factor. Arguably, this fact alone should provide grounds to appeal a decision. This is the logic of epistemic debunking. In addition, debunking arguments seem worthwhile to explore when rights are balanced or reasons weighed, a notoriously opaque process, susceptible to distortive influences.

\section{B. Target: Human Rights}

In the next step, I wish to apply these arguments to a topic that lies between positive law and philosophy of law, the justification of human rights. I do so mainly for two reasons: human rights seem to be the kind of entities that come closest to the conception of rights presupposed by Greene. Moreover, justifications of human rights are usually so controversial that right answers are hard to find. In such conditions, debunking arguments promise help.

Greene's attack is directed against rights as a class of normative entities. But properly understood, he targets only those rights that conflict with consequentialist reasoning, nonconsequentialist rights. His argument also presupposes a specific conception of rights as all-things-considered, almost absolute claims. This does not correspond to rights as used in the law, i.e., as prima facie positions regularly balanced against, or reconciled with, other rights. It is thus tempting to quickly dismiss Greene's argument from a legal perspective. However, charitably read, it may be reconstructed to apply to several types of rights, particularly extraordinarily strong ones such as absolute, human, or constitutional rights. Absolute rights trump other rights or interest per definitionem. International human rights law

49. Of course, one may hold that being biased implicitly violates other norms, such as judicial impartiality, even if it does not include self-interest. That may be the case. But then, insofar as the norm is meant to secure correct outcomes, it follows the logic of debunking, which underscores rather than refutes its applicability to the law.

50. Shai Danziger, Jonathan Levav \& Liora Avnaim-Pesso, Extraneous Factors in Judicial Decisions, 108 Proc. NAT'L ACAD. ScIs. 6889 (2011); cf. Keren Weinshall-Margel \& John Shapard, Overlooked Factors in the Analysis of Parole Decisions, 108 Proc. Nat'L Acad. Scis. E833 (2011); Shai Danziger, Jonathan Levav \& Liora Avnaim-Pesso, Reply to Weinshall-Margel and Shapard: Extraneous Factors in Judicial Decisions Persist, 108 Proc. NaT'L Acad. Scis. E834 (2011); Andreas Glöckner, The Irrational Hungry Judge Effect Revisited: Simulations Reveal that the Magnitude of the Effect Is Overestimated, 11 Judgment \& Decision Making 61 (2016); Christoph Bublitz, What Is Wrong with Hungry Judges?, in LaW, Science, Rationality 1 (Antonia Waltermann, David Roef, Jaap Hage \& Marco Jelicic eds., 2020). 
and domestic constitutional laws recognize a few of them, from the abolition of slavery and the prohibition of torture in Articles 4 and 5 of the Universal Declaration of Human Rights to the protection of human dignity in Article 1 of the European Charter of Fundamental Rights and Freedoms. These guarantees are conceived as so strong that they cannot be outweighed by opposing rights or interests, some not even in times of emergency. ${ }^{51}$ However, the absolute character of these rights requires justification in light of cases in which countervailing rights and interests are so pressing that their principled priority is not self-evident (e.g., ticking bombs, see infra).$^{52}$ Greene provides a psychological explanation: acts of torture or violations of dignity evoke intuitive System 1 aversions so intense that overriding them through System 2 considerations becomes impossible; to thinkers, this seems inconceivable. ${ }^{53}$

Moreover, some nonabsolute but extraordinarily strong rights, especially human and constitutional rights, regularly prevail over ordinary rights and public interests. One may ask with Greene where their strength derives from, whether they truly deserve to be so strong, and, in particular, why they need additional protection, over and above the weight that the underlying interests would have in a consequentialist analysis. In this sense, the following argument examines whether these rights are justifiable. (And to be more precise: it concerns individual rights, not the class of rightstokens, not types-and it concerns legal human rights, not moral or natural ones. $)^{54}$

\section{Mode of Existence of Human Rights}

The question is whether a specific human right to $\mathrm{X}$ is justified (not whether it is recognized in positive domestic or international law). It is assumed that the mode of existence of human rights is justification in the sense that the better reasons, all-things-considered, speak in its favor. This stands in contrast to a "metaethical realist" view on human rights according to which they exist as mind- or reason-independent entities "out there." If

51. Nonderogable rights are listed, for example, in Article 4 of the International Covenant on Civil and Political Rights.

52. Surely, history has provided ample reasons and many instances of dramatic misuse of state powers that strongly suggest shunning such practices. But although historical arguments have merit, they may be insufficient to fully sustain nonexceptional absolute rights. Also, offered in-principle justifications usually do not appeal to history, but to some more substantive argument; those may be weaker than the strength of the right suggests. Interestingly, the mere writing of these words provokes an inner urge to declare full endorsement of these rights. But the fact that even asking questions about justification provokes strong reactions might precisely be key to Greene's point. Some human rights violations evoke such strong reactions that one may not engage in thorough reflection on the wrongness of the deeds and possible exceptions.

53. It should be noted that although Greene's critique is in line with traditional consequentialist critics of human rights, he explicitly acknowledges that some rights are indeed absolute even on consequentialist grounds. GREENE, supra note 6, at 309.

54. In Greene's argument, debunking of beliefs in some rights can be generalized to the entire class of human rights. This requires that every belief in human rights have been formed in defective ways. This is likely not the case. 
that "metaethical realist" view was correct, human rights are discoverable as (in the words of some philosophers: "queer") facts of the world. Then, the problems of epistemology as previously outlined in the shooting star example would apply. The more plausible but theoretically more challenging position is a "constructivist" view according to which human rights exist if, and only if, they can be justified. I will adopt this more challenging position in the following.

More precisely, the object of debunking is confidence in the belief that the right exists, i.e., that all-things-considered, the better arguments speak in its favor. Debunking aims to undermine this confidence, its epistemic credence. Note that the argument only applies to all-things-considered judgments that (implicitly) entail a claim to correctness, i.e., that they are the most persuasive position with respect to the matter at hand. The argument does not, by contrast, apply to beliefs that arise from partisan, one-sided claims brought forward in the interest of a party abound in litigation and politics. They present the most favorable case for a specific position, but neglect counterarguments in anticipation that they will be provided by the opposing party. Such one-sided reasoning fails to confer epistemically justified confidence in the truth of its results.

Adopting the judicial perspective is helpful: imagine a judge who must decide a case that decisively turns on the existence of the human right in question. She is not bound by positive law and has to take into account all principles of law as well as legal and political philosophy (including other human rights). She has to make a decision ("forced choice"). She is presented with arguments from both sides, and every claim of one side is contested by the other; there is no agreement. Suppose the judge forms the belief that the better arguments support the existence of the right, and decides accordingly. Can this judgment be debunked? ${ }^{55}$

\section{A Legal Debunking Argument}

The following argument is a variation of dual-process debunking and builds on Greene's idea that intuitive System 1 outputs can be defective. But contrary to Greene, the problem is not the susceptibility of intuitions to "morally irrelevant factors." Rather, the process is defective with respect to other conditions of the justification of rights, which System 1 processes and IR-reasoning cannot fulfill. I shall call them the justifiability condition and the generalizability condition.

55. One may wonder why the judge should be bound by other principles of law, as human rights may transcend all (human-made) laws. However, if we are interested in legal human rights that are applicable to legal matters in legal institutions, they should not contravene foundational legal principles, such as those that will become relevant infra, for example judicial impartiality. Still, of course, there might be tensions between specific human rights or principles that need to be reconciled. But that presupposes their prior recognition. 


\section{Justifiability}

Rights are relational and correlative. They exist in relation between persons; claims of right-holders correlate with duties of duty-bearers. ${ }^{56}$ The existence of a right of the former inherently limits freedoms of the latter. As a general principle, setbacks to freedoms have to be justified vis-à-vis those affected. Arguments in favor of rights must therefore not only explain why a right is of great value to right-holders, but primarily why it is justified to impose it on duty-bearers. ${ }^{57}$ Furthermore, legal justifications have to observe the general principle of law that all sides be heard, audi alteram, which entails that everyone's concerns are sufficiently appraised. Every party must have a fair chance of affecting the outcome of a legal decision. Although some concerns ultimately have to yield, they must be properly acknowledged and shall not be dismissed a limine. Accordingly, the decision-maker has to have an open, not predetermined mind. Ideally, she is fair-minded and reserves judgment until all sides of an argument have been heard and understood. These are general ideas of law, manifested in various forms, depending on specificities of legal systems, e.g., in rules of administrative law about mandatory hearings, or in the idea of a fair trial. In the common law tradition, they are considered part of "natural justice." This is not merely a procedural requirement, or one that secures the appearance of impartiality. It is a necessary ingredient in persuasive justifications of rights. Arguments in favor of rights that fail to give due consideration to the duties they impose and to concerns of duty-bearers are regularly bad arguments in light of the "better argument, all-things-considered" standard. As a consequence, confidence in their correctness is not warranted.

\section{Generalizability}

In addition, human rights require universalizability, or at least a large degree of generalizability. As human rights are among the most abstract and general entities inhabiting the legal sphere, they have to be persuasive with respect to a great many cases and circumstances. Schauer considers "second order reasoning" a hallmark of good legal reasoning; it is the skill to transcend the particular case, avoiding a quick judgment that appears fitting for the present case and instead considering a range of hypothetical scenarios to find a generalizable rule. Even when solving a concrete case, the particular has to be overcome. ${ }^{58}$ Arguments in favor of a human right have to stand the test of generalizability; without it, confidence in its suitability is not warranted. Moreover, various human rights are

56. This is at least true for human rights of the kind presently accepted in international law. That in some conceptions some rights do not correlate with duties is irrelevant here.

57. The argument gains persuasive power if one considers other people-rather than the state-as duty-bearers, for instance in a social contract model. But even if one considers human rights to apply only in the vertical state-citizen relation, the duties indirectly affect other citizens (mediated over public interests).

58. Frederick Schauer, Is There a Psychology of Judging?, in The Psychology of Judicial Decision MaKING 103 (David E. Klein \& Gregory Mitchell eds., 2010). 
"interdependent and interrelated." ${ }^{59}$ Adding (or subtracting) a right may alter the architecture of mutually supportive rights. Convincing arguments need to recognize such structural effects. ${ }^{60}$

The generalizability condition is a conceptual requirement of a universal human right; the justifiability condition derives from political philosophy and is a hallmark of a just legal order. I shall assume without further argument that there is no plausible construal of a human right that contravenes these two broadly accepted principles. From them, we can derive conditions for convincing arguments affirming the existence of a human right. They must show that the right is adequately justified with respect to the burdens it imposes on dutybearers, and this has to generalize to a range of cases. This already allows for a striking observation: many of the particularly spirited calls for a particular human right seem imbalanced as they strongly emphasize the benefits they bring for potential right-holders but underappreciate the burdens they impose on others. Such arguments fall short of meeting the justifiability condition. Furthermore, some contemporary politically motivated calls for human rights, arising in the face of more or less specific cases and causes (e.g., a "human right to internet," "a right to be forgotten") seem not sufficiently tested for generalizability. Respective beliefs can then be debunked. ${ }^{61}$

\section{E. Psychology of Human Rights Justifications}

In the final step, these two normative conditions have to be related to the psychology of forming beliefs. Justifiability requires taking into account opposing considerations; generalization requires contrafactual and hypothetical as well as rule-based thinking. These are operations of which System 1 mechanisms are incapable. ${ }^{62}$ Recall that System 1 mechanisms can compute a few aspects only; they lack access to all forms of memory,

59. World Conference on Human Rights, Vienna Declaration and Programme of Action, U.N. Doc. A/CONF.157/23 (June 25, 1993).

60. Of course, with respect to new rights, one could resort to some of the quality controls suggested in the literature and check whether System 1 reasoning can satisfy them (it cannot), e.g., Philip Alston, Conjuring Up New Human Rights: A Proposal for Quality Control, 78 Am. J. Int'L L. 607 (1984).

61. Let us address one objection that might be directed against the justifiability condition. It might be held that it is not necessary that everyone be heard or that concerns have at least a theoretical chance to affect outcomes, at least with respect to absolute rights. By definition, they prevail over other considerations. Listening to concerns of affected persons is more a gesture. It does not affect the outcome; it cannot do so. That is not a shortcoming of reasoning but the nature of absolute rights. The premise is thus wrong. In reply, a further differentiation needs to be made. At the level of rights application, absolute rights indeed always prevail. But presently, we are primarily interested in the level of justification. There, it is not evident that other concerns should not play a role, at least in some hypothetical form. Arguments in favor of absolute rights must make a plausible case that countervailing concerns can and should never override them. This requires recognizing these concerns as well as generalizing them. At that level, the normative premise and, therewith, the debunking argument, still applies. However, there might be deontological arguments in favor of absolute rights that do not pose these requirements. But it is hard to assess in the abstract whether those arguments are plausible.

62. See the quotation by Evans and Frankish, text accompanying note 21, supra. 
cannot transcend the present context, and are associative and stereotypical. ${ }^{63}$ System 1 does not allow for abstractions, generalizations, or, especially, rule-based reasoning, which are the main feature of Schauer's "second order reasoning." Hypothetical, contrafactual, and open-ended thinking are features of System 2 reasoning. Therefore, System 1 reasoning is insufficient to generate beliefs that satisfy the justifiability and generalizability conditions. Whatever the output of System 1, it has been generated by mechanisms unable to perform necessary operations.

By contrast, System 2 is capable of these operations. It can critically engage with System 1 outputs, consider counterarguments, and generalize rules in light of hypothetical cases. However, if System 2 only rationalizes System 1 outputs, as in IR-reasoning, it fails to adequately appreciate or accommodate opposing concerns of duty-bearers, or generalize relevant considerations-this is the nature of rationalization as laid out above. ${ }^{64}$ Post hoc rationalizing is predetermined reasoning; countervailing reasons have no chance, or hardly a chance, of succeeding. ${ }^{65}$ Accordingly, IR-reasoning does not satisfy the justifiability and generalizability conditions either. System 2 rationalization of defective System 1 outputs does not confer epistemic credence. Thus, System 2 reasoning is necessary for persuasive arguments but not sufficient; nonrationalizing reasoning is required. As a consequence, IR-reasoning falls short of carrying out the mental operations necessary to meet the justifiability and generalizability conditions. It is not a reliable process for forming epistemically justified beliefs about human rights. So formed beliefs are debunkable. ${ }^{66}$

We have now established a debunking argument from legal premises. It is based on empirical deficits of System 1 reasoning according to the dual-process model, and on the epistemic defects inherent to rationalization. ${ }^{67}$ Formally:

Person P holds a belief (HR) in favor of the existence of a human right. p1: The belief HR originated in a System 1 process [empirical premise 1].

63. See, e.g., the chart in Jonathan Evans, Dual-Processing Accounts of Reasoning, Judgment, and Social Cognition, 59 Ann. Rev. Psych. 225 (2008).

64. See the epistemic defects of rationalizing reasoning, supra.

65. Of course, this may at some point turn into a threshold question: no judge will enter deliberation with a blank slate. Some jurisdictions try to draw a distinction between predisposition and predetermination. See Philip Havers \& Alasdair Henderson, Recent Developments (and Problems) in the Law on Bias, 16 Jud. Rev. 80 (2011). The fact that there are grey areas does not, however, undercut the present argument.

66. But even with concessions to a more favorable picture of intuitions, it is clear that they, alone, are insufficient to provide good justifications for rights. Of course, after long and open deliberations, experts may develop "learned intuitions"; the judicial hunch is a good example. However, this presupposes that at some prior stage, nondefective reasoning has taken place. That might have been the case and debunking fails. The empirical premise is simply wrong. However, it only shifts the problem back. The question is, then, how those initial beliefs that then became intuitions were formed. Thus, reference to learned intuitions is of no avail here.

67. To make clear: the debunking argument does not equally apply to beliefs in consequentialist norms, as they are formed on different causal routes, not through IR-reasoning (so Greene assumes). 
p2: System 1 processing considers neither opposing information nor counterfactuals. It is also unable to subject outputs to a test of generalizability [empirical premise 2].

p3: Justifications of human rights must meet the justifiability condition, i.e., require proper recognition of duty-bearers' concerns, and this presupposes due consideration of opposing information [normative premise 1].

p4: Justifications of human rights require generalizability [normative premise 2].

Conclusion 1: System 1 processing is not a reliable (defective) process for justifications of human rights.

Conclusion 2: HR emerges from an unreliable process.

p5: HR was subsequently rationalized through System 2 [empirical premise 3].

p6: Rationalization is an unreliable process, i.e., it does not justify beliefs [normative premise 3].

Conclusion 3: HR was formed through unreliable processes.

Conclusion 4: $\mathrm{P}$ is not justified in believing HR.

\section{F. Why Are Intuitions Not a Valid Source?}

One might feel unpersuaded as to why intuitions should not be a valid source for beliefs. In fact, one may hold them to be the foundation of human rights. They may express a universal moral grammar. The historical drafting of the Universal Declaration of Human Rights is sometimes portrayed as the attempt to find common intuitions, rather than more elaborated justifications. 68 "We can agree on the rights, but not on a justification" is a famous phrase attributed to Jacques Maritain, a leading figure in the background of the drafting. ${ }^{69}$ Moreover, it seems that there are clearly true intuitions, such as that tormenting innocent children, or rape, is wrong.

To clarify: provided that these intuitions are indeed universally shared, the present argument does not disqualify them as a foundation of human rights. They can be part of a specific form of justification, a contractarian one, rights by agreement. If everyone agrees about a right, it is a good candidate for a right in a democratic legal order. Nonetheless, it might still be incorrect according to more demanding forms of justification. To assess its truth or correctness, an independent standard, free from influences of intuitions, is required. Furthermore, it is assumed here that every claim is contested, i.e., that duty-bearers reject the right in question and demand

68. It should be noted that Mikhail derives an argument to the contrary conclusion, supportive of human rights, from this fact. John Mikhail, Moral Grammar and Human Rights: Some Reflections on Cognitive Science and Enlightenment Rationalism, in Understanding Social Action, Promoting Human Rights 160 (Ryan Goodman, Derek Jinks \& Andrew K. Woods eds., 2012); see also David Enoch, On Analogies, Disanalogies, and Moral Philosophy: A Comment on John Mikhail's Elements of Moral Cognition, 8 Jerusalem Rev. Legal Stud. 1 (2013), and the reply, John Mikhail, New Perspectives on Moral Cognition: Reply to Zimmerman, Enoch, and Chemla, Egre, and Schlenker, 8 Jerusalem Rev. Legal Stud. 66 (2013).

69. See C.M.A. McCauliff, Cognition and Consensus in the Natural Law Tradition and in Neuroscience: Jacques Maritain and the Universal Declaration of Human Rights, 54 VILL. L. REv. 45 (2009). 
justification. They may not share the intuition or dismiss its normative relevance. This cannot be rebutted by appealing to the intuition. Moreover, the present argument does not contend that intuitions are wrong-that would be a misreading. It only claims that they are insufficient, and that arguments drawing on them fall short of providing epistemically justified beliefs.

After all, the foregoing demonstrates how beliefs formed in a specific way can be debunked and thus opens a route from psychology to normative justification. It involves normative premises derived from general principles of law, and the psychological premises seem to be true at least in some legal decisions (those made through IR-reasoning). A legal debunking argument has been established.

\section{PRACTICAL APPLICATION}

In the final section, I shall briefly sketch how this argument can be applied to concrete rights. Let us recall which beliefs about rights are potentially affected: all beliefs formed through IR-reasoning. Which particular beliefs are so formed is an empirical question that needs to be tested. According to Greene, all nonconsequentialist rights are so formed, i.e., all rights that claim priority over outcomes of cost-benefit calculations. Whenever we feel a deontological sting that keeps us from endorsing consequentialist interest maximation, we allegedly succumb to defective reasoning processes, which make us believe that there is a persuasive reason against the consequentialist position. Familiar examples of this conflict are the right against torture if torture would yield overall better consequences (saving many), or freedoms of speech and religion when curbing them would overall increase welfare. Another prime candidate for psychological debunking is the right to human dignity, the paramount value of the recent European Charter of Fundamental Rights and Freedoms. Philosophers struggle to understand its meaning, scope, and justification, whereas many legal systems and scholars are convinced that dignity is absolute and inviolable. This is a striking difference. Greene's account provides an experimentally testable hypothesis for it: the belief in the absolute nature of dignity arises from emotionally laden intuitions elicited by typical violations-humiliating, degrading, demeaning, disgusting behavior. These intuitions are so entrenched that they cannot be overridden by other considerations. It would be worthwhile to examine this experimentally. Further debunkable rights that Greene mentions are the right to sell or donate organs and the right against being subjected to the death penalty. An interesting case is abortion, where both pro-life and pro-choice sides seem strongly driven by IR-reasoning. ${ }^{70}$ Debunking arguments of both sides could clear the way for better arguments. Further examples of claims that may arise from

70. Greene discusses abortion at length Moral Tribes: Emotion, Reason, and the Gap Between Us and Them, supra note 6 , at 310 et seq. 
defective psychological processes, but that are not human rights, include the state's right to impose retributive punishment, or the criminalization of harmless yet intuitively reprehensible behaviors such as voluntary incest among adult siblings. ${ }^{71}$ Systematic scrutiny of legal orders would yield a range of further norms that elicit strong intuitions and seem to prevail in a principled manner over outcomes of cold cost-benefit calculations. They are potential debunking targets. However, contra Greene, I suspect that this is not true for more abstract human rights, such as the one to peaceful assembly. But this is ultimately an empirical question.

Many arguments about the justifiability of the just-mentioned rights show the typical stalemate: although arguments pro and con have been comprehensively exchanged, no consensus is reached. Psychological debunking may advance the debate. This would require psychological investigations into the forming of beliefs grounding them. This is easy in theory and very difficult in practice. One way of investigating is examining people while they form beliefs about the right in question, using the methods of contemporary moral psychology. This requires complex experiments, possibly involving brain imaging during moral reasoning, as in studies by Greene and Haidt. It may not be feasible to conduct such studies with subjects who have thought intensely about such questions and have acquired learned intuitions, as the original processes of belief acquisitions are of interest. But questions might be studied with young, inexperienced subjects, and experts can be tested with respect to novel and unfamiliar rights. The general challenges in conducting such experiments and in operationalizing normative questions are demonstrated by the decade of debate around Greene's Trolley studies. Much can be learned from them. If Greene's hypothesis is true, these investigations will show that the beliefs affirming nonoverridable legal positions with respect to dignity or torture are formed through IR-reasoning. By contrast, belief formation in subjects who are not persuaded by categorical arguments pro dignity and contra torture will be psychologically different, with less System 1 involvement. This is the prediction of Greene's model-and combined with the presented normative argument, the realization of the prediction could have legal implications.

Moreover, if the IR-reasoning hypothesis proves correct in one experiment, another round with new subjects, cases, arguments, and beliefs is necessary. But if, by contrast, some pro-rights beliefs are formed through routes other than IR-reasoning, Greene's hypothesis is falsified. This would strengthen confidence in the belief. Results of this research program are open. But in any case, by uncovering the psychological mechanisms behind legal beliefs, interdisciplinary research may shine new light on a range of intriguing legal questions, and if the present argument is sound, it may have normative consequences. Furthermore, we can already start today to improve our legal reasoning by becoming aware of our intuitions and

71. Haidt, supra note 23. 
attempts to rationalize them. We can give more weight to the counterintuitive position and try to suspend judgments longer. Psychological advice for more System 2 and less System 1 thinking, specifically tailored to legal reasoning, might be developed. The present debunking argument provides a good reason for doing so.

\section{CONCLUSION}

How many beliefs in rights are formed through IR-reasoning is an open empirical question; pace Greene, Haidt, and others, it might be the exception rather than the rule. IR-reasoning is the characteristic belief-forming mode of partisan politics, litigation, outrage, and polarization on social media. How far this extrapolates to expert discourse, scholarly arguments refined over years of written exchange, and institutionalized ways of forming and shaping beliefs remains to be seen.

However, many human rights claims seem to appeal to intuitions that elicit strong images and condemnatory attitudes, highlighting the injustice done to people. The Preamble to the UN Declaration grounds human rights in the opposition to atrocities that "outrage the conscience of mankind." The Preamble to the Rome Statute of the International Criminal Court speaks about atrocities that "shock the conscience." These prominent references to intuitive moral reactions strongly support the idea of an affective intuitive component in human rights justifications. It goes without saying that the horrors of the Holocaust, World War II, and other atrocities are indeed shocking and not to be trivialized, and that the adoption of the Universal Declaration was a humanistic milestone. Nonetheless, arguments may be more convincing if they run differently. Contrast these statements with a ruling by the European Court of Human Rights on judicial impartiality: " $[\mathrm{T}]$ he emphatic language used by the judges throughout their decision conveyed a sense of indignation and shock, which runs counter to the detached approach expected of judicial pronouncement." ${ }^{, 2}$ What is needed, and what legal scholarship may provide, are arguments that neither shock conscience nor evoke outrage-but are nonetheless compelling. From a legal theoretical perspective, that is an interesting conclusion. ${ }^{73}$

Debunking opens legal justifications to psychological research, in virtue of the insight that good legal reasoning has psychological conditions; the absence of the latter may point to the absence of the former. Debunking allows beliefs without argument on the merits. That is remarkable. But, by the same token, it is only selective and should not be mistaken for falsification: other arguments for the debunked belief can be brought forward. They may invite a further route of debunking that might fail or succeed.

72. Kyprianou v. Cyprus, App. No. 73797/01 (Eur. Ct. H.R., Grand Chamber, Dec. 15, 2005).

73. It may pose the additional difficulty that particularly severe acts may regularly elicit hard-to-override emotional intuitions. 
And as long as good arguments do not run out, this process goes on. Debunking is unable to ever truly falsify a belief. It may only eliminate confidence. But that, by itself, confers an interesting new angle on legal argumentation.

Finally, by exposing weaknesses and distortive factors, debunking arguments open the view to better arguments that do not fall prey to such objections. One should strive to avoid shortcomings that debunking arguments explore and instead aspire to formulate arguments that are less strongly supported by System 1 and less prone to subsequent rationalization. ${ }^{74}$ Correspondingly, and perhaps somewhat paradoxically, counterintuitive arguments have an epistemic advantage as they have not been formed in the defective way outlined here. In the long run, this may stabilize or vindicate human rights. ${ }^{75}$ This requires arguments not based on IR-reasoning. Whereas Greene may hold that this is impossible, I am confident that with respect to the rights enumerated in the Universal Declaration and the Covenants, particularly of the first generation, persuasive nondebunkable arguments can be forwarded. The fact that many arguments in favor of human rights are strong and passionate does not rule out that persuasive impassionate arguments can be made. Empirical science is far from having shown the contrary, and legal theory should accept the challenge that their findings pose.

74. From a different angle, Cass Sunstein writes that legal institutions should provide "deliberative checks" on System 1 reasoning. Cass R. Sunstein, Some Effects of Moral Indignation on Law, 33 VT. L. REv. 405 (2008).

75. For the vindication of normative claims through reversing debunking arguments, see SAUER, supra note 1; Victor Kumar, Moral Vindications, 167 Cognition 124 (2017). 